\title{
LUDICIDADE NA MATEMÁTICA
}

\author{
Patrícia Carolina de Souza Pereira ${ }^{1}$ \\ Beatriz Miranda Moreira ${ }^{2}$ \\ Marlete Fernandes Arifa ${ }^{3}$
}

RESUMO: Aprender matemática é muito mais que saber contar, é necessário compreender o conceito de números. Diante dessas dificuldades, surgem algumas dúvidas: como os professores podem usar a ludicidade para trabalhar com os alunos? Quais os desafios no ensino de matemática? Como a ludicidade pode contribuir para o aprendizado do aluno? Dessa forma, este trabalho tem como objetivo destacar a importância de trabalhar a ludicidade nas aulas de matemática no dia a dia das crianças, possibilitando uma visão positiva acerca da aprendizagem dessa disciplina. Pretendeuse, na metodologia utilizada, realizar uma revisão bibliográfica sistemática que trouxesse, por meio de referências teóricas, o quão a ludicidade é importante no processo de ensino-aprendizagem de matemática, pois trabalhar com o lúdico torna as aulas práticas atrativas para os alunos e os educadores obtêm melhores resultados em sala. Diversos autores ressaltam que os jogos podem ser utilizados com a finalidade de facilitar o aprendizado, como construir conceitos e memorização de processos, pois, ao mesmo tempo em que jogam, os alunos estão exercitando a capacidade de concentração e de atenção e aprendem a elaborar hipóteses, estabelecendo alternativas diferentes, se organizando da melhor forma para solucionar os problemas. Conclui-se que a ludicidade na matemática desempenha papel importantíssimo para se obter sucesso na prática educativa.

Palavras-chaves: Covid-ı9. Educação infantil. Ensino-aprendizado. Ludicidade na matemática. Lúdico.

ABSTRACT: Learning math is much more than knowing how to count, it is necessary to understand the concept of numbers. Given these difficulties, some questions arise: how can teachers use playfulness to work with students? What are the challenges in teaching mathematics? How can playfulness contribute to student learning? Thus, this work aims to highlight the importance of working with playfulness in math classes in children's daily lives, enabling a positive view of math learning. It was intended in its methodology to carry out a systematic bibliographic review that brings through theoretical references how playfulness is important in the teaching process of mathematics learning, where working with play makes practical classes attractive for students, and educators obtain better

IGraduação em Bacharelado em Ciência da Computação (Universidade José do Rosário Vellano, UNIFENAS, Brasil), Especialização em Metodologia do Ensino na Educação Superior (Centro Universitário Internacional, UNINTER, Brasil) e mestrado Profissional em Sistemas de Produção na Agropecuária (Universidade José do Rosário Vellano, UNIFENAS, Brasil).

${ }^{2}$ Graduação em Pedagogia (Universidade José do Rosário Vellano, UNIFENAS, Brasil).

${ }^{3}$ Graduação em Pedagogia (Universidade José do Rosário Vellano, UNIFENAS, Brasil). 
results in the room. Several authors point out that games can be used with the purpose of facilitating learning, such as building concepts and memorizing processes, while playing is exercising their ability to concentrate, pay attention, learn to elaborate hypotheses, establishing different alternatives by organizing themselves in the best way to solve the problems. It is concluded that playfulness in mathematics plays a very important role in achieving success in educational practice.

KEYWORDS: Covid-19. child education. teaching-learning. playfulness in mathematics. ludic.

\section{INTRODUÇÃO}

Ensinar e aprender matemática vai muito além de questões que se veem nos livros. Aprender matemática é muito mais que saber contar, é necessário compreender o conceito de números. No ano de 2020, o mundo viveu e ainda vive uma pandemia pela disseminação do novo coronavírus. Diante desse cenário, tanto a rede pública, quanto a particular tiveram que se reinventar e utilizar novos métodos de ensino. As aulas deixaram de ser presenciais, tornando-se remotas e online, os pais deveriam auxiliar os filhos durante as atividades, a ludicidade, desde então, se tornou grande aliada do corpo docente durante o ensino-aprendizado, fazendo diferença, principalmente, na vida de pais que têm dificuldades em ensinar os filhos.

Diante dessas dificuldades, surgem algumas dúvidas: como os professores podem usar a ludicidade para trabalhar com os alunos? Quais os desafios no ensino de matemática? Como a ludicidade pode contribuir para o aprendizado do aluno? Neto (2017) ressalta que atividades lúdicas geram prazer e satisfação ao serem desempenhadas, além de possibilitarem à criança uma nova interpretação de mundo onde ela desenvolve habilidades que, até então, desconhecia. Assim, ao solucionar algum problema através de um jogo, a criança recria soluções para situações vividas.

Ao analisar a brincadeira como resultado da atividade criadora humana, Borba (2007, p. 35) evidência:

\footnotetext{
O brincar é uma atividade humana criadora, na qual imaginação, fantasia e realidade interagem na produção de novas possibilidades de interpretação, de expressão e de ação pelas crianças assim como de novas formas de construir relações sociais com outros sujeitos, crianças e adultos. Tal concepção se afasta da visão predominante da brincadeira com atividade restrita à assimilação de códigos e papéis sociais e culturais, cuja função principal seria facilitar o processo de socialização da criança e sua integração à sociedade.
} 
Assim, utilizar novos meios para facilitar a aprendizagem do aluno como jogos e dinâmicas proporcionará à criança um aprendizado mais prazeroso além de instigar a curiosidade e a imaginação. Inserir a ludicidade surge como alternativa no aprimoramento da prática pedagógica do docente de modo a propor uma melhor compreensão e assimilação dos conteúdos matemáticos por parte do aluno.

O professor deve usar novos métodos que despertem a curiosidade das crianças e a ludicidade vem para isso. Segundo Costa e Soares (2015), o professor é um mediador da aprendizagem, gerando na criança capacidades para manusear materiais, interagir com colegas e resolver situações-problema. Nesse contexto, deve traçar objetivos e o que deseja alcançar através da ludicidade de modo que professores e alunos participem das brincadeiras que fazem parte do aprendizado, do imaginário e do desenvolvimento intelectual.

Sendo assim, a Matemática se faz presente na vida na criança desde a primeira infância até à universidade. A ludicidade tem papel fundamental tanto no desenvolvimento quanto no processo de construção do conhecimento infantil, tornando mais fácil o aprendizado e a interação, tanto em aulas presenciais quanto em remotas.

No processo ensino-aprendizagem, muitas são as dificuldades encontradas, não somente pelos alunos, mas também pelos professores. Dessa forma, este trabalho tem como objetivo destacar a importância de se trabalhar a ludicidade nas aulas de matemática no dia a dia das crianças, sendo esta uma facilitadora de elevada importância para o desenvolvimento infantil, possibilitando uma visão positiva acerca da aprendizagem de matemática, uma vez que muitos estudantes têm um pensamento negativo sobre essa disciplina. Também serão apresentadas teorias sobre a importância do lúdico em sala de aula para que professores possam trabalhar com os alunos em tempos normais e em tempos de pandemia, em que o ensino é remoto.

\section{REFERENCIAL TEÓRICO}

\section{I.I A importância da matemática no dia a dia}

Estudar matemática vai muito além de somar e de subtrair números. A matemática desenvolve na criança a capacidade de resolver problemas além de despertar nela o hábito 
da investigação. Se se parar um instante para observar, os números fazem parte do cotidiano, e pela correria do dia a dia, passam despercebidos. Estão no relógio para ver as horas, no despertador, quando para acordar, nas receitas culinárias indicando a quantidade de ingredientes, entre outros tantos lugares. Segundo Cortês (2020), a matemática é tão intensa no dia a dia, que não se pode viver sem ela.

Quando se vai ao supermercado fazer compras, a matemática nos acompanha desde a chegada até à saída. Vamos ao supermercado para adquirir uma quantidade $\mathrm{X}$ de produtos; destes, cada um contém uma sequência de números de identificação, códigos de barras, datas de validade e lote de fabricação. Ao passar os produtos no caixa, na tela do computador, irão aparecer a quantidade de produtos e a somatória do valor deles; para finalizar, paga-se pela mercadoria a qual está sendo comprada, seja no dinheiro, no cheque ou no cartão. A matemática está presente na vida de todos e, ao ensinar através dos jogos, a criança aprende com mais facilidade (SANTOS, 2014).

A matemática está presente na psicologia e na sociologia, nas quais resultados são analisados, e, posteriormente, comparados. Na hidroginástica, os movimentos dos exercícios devem ser contados e repetidos uma série de vezes; na biologia, em busca da quantidade de moléculas que produzem uma reação química; no teatro para a demarcação de espaços, a duração de peças e para calcular a intensidade da luz no palco.

Santos (2014), afirma que, na escola, além de estudar, a criança também deve interagir e brincar com as demais e o jogo e a brincadeira funcionam como um laboratório para o aprendizado. Assim, a matemática se faz presente no jogo de damas, no xadrez, na sinuca, nos impostos, nas contas de água e luz, enfim, no dia a dia. Ela se faz presente no tempo que transcorre através dos dias, dos meses e dos anos.

Apesar de tão presente na vida cotidiana, a matemática ainda não é bem aceita pela comunidade discente, pois exige memorização e raciocínio, e muitos alunos apresentam algumas dificuldades e acabam julgando a matemática como uma matéria ruim ou simplesmente não a aprovam. A matemática "é a ciência das grandezas e formas no que elas têm de calculável e mensurável, isto é, que determina as grandezas uma pelas outras segundo as relações existentes entre elas" (BUENO, 2007, p. 500). 
Considerada uma disciplina essencial nas escolas, a matemática é muito utilizada no dia a dia. Presente em todas as profissões e áreas da educação, proporciona conclusões ou deduções para determinado problema. Segundo Souza (200I), o ensino-aprendizagem da matemática é fundamental na formação do ser humano e do currículo escolar, sendo assim indispensável para uma boa formação.

Aprender matemática auxilia na formação intelectual da criança, seja pelo pensamento lógico, seja pela intuição, pela imaginação e pelo raciocínio dedutivo e indutivo (SOUZA, 20oI). Com o passar do tempo e com o avanço da tecnologia, a matemática tornou-se indispensável no cotidiano, pois está ligada a vários setores como saúde, finanças, engenharia, arquitetura, entre outros. Em suma, é uma ciência que vai nos acompanhar por toda a vida.

\subsection{O ensino tradicionalista da matemática nos anos iniciais do ensino fundamental}

A matemática foi introduzida na sala de aula após a Revolução Industrial (final do século XVIII), pois as administrações, produções e sistemas bancários exigiam cada vez mais de cada pessoa. Nessa época, o estudo da matemática se baseava no raciocínio dedutivo de Euclides (século III A.C) que fazia uso de linguagens inapropriadas para dar início à disciplina na educação básica.

Com o passar do tempo, após o período de guerra, o número de crianças nas escolas teve um elevado crescimento e a matemática continuava sendo ensinada através dos métodos tradicionais de ensino. Assim sendo, mais crianças passaram a ser reprovadas, pois o ensino tradicional que era passado até então não poderia ser aplicado à realidade da criança. Segundo Silva (2015, p. 16), esse problema está ligado à utilização de materiais didáticos antigos, que não despertam interesse algum no educando quando propostos porque não têm ligação com as necessidades deles.

Após a década de 1930, com os avanços tecnológicos, os norte-americanos interessaram-se em formar novos cientistas nas escolas. A partir dessa perspectiva, um novo currículo para a matemática foi elaborado. A Matemática Moderna, assim chamada, não seguiu adiante devido à falta de didática apropriada aos alunos do ensino fundamental. Assim, não era viável. As adversidades que o ensino tradicional da matemática causou 
atingiram uma proporção tão grande que foi preciso que estudiosos da época dessem início a um estudo sobre Educação Matemática, na década de 1970, atingindo assim, estudiosos do mundo inteiro.

Santos (2020) caracteriza o ensino tradicionalista como um ensino que deve manter o aluno atento, ouvindo e permanecendo em silêncio. Após estudarem técnicas e diferentes soluções, surgiu a necessidade de um método diferenciado de aplicação, de modo que se relacionasse com a vida do aluno e seu cotidiano, ligando, assim, a matemática com a psicopedagogia.

Assim sendo, em 1997, esse movimento chegou até o Brasil através do Parâmetro Curricular Nacional (PCN). Esse documento continha informações necessárias para um ensino de matemática excelente. $\mathrm{Na}$ escola, a matemática é vista como uma ciência capaz de recodificar a realidade e de estabelecer diferenças, pois a criança, ao realizar atividades, deve manipulá-las de forma que venha a construir uma aprendizagem significativa. Porém, devido à prática tradicionalista de alguns professores, a construção desse conhecimento pelos alunos está a perder de vista. A prática tradicional impede que alguns alunos construam um aprendizado voltado para o cotidiano e para a realidade vivida.

Infelizmente, alguns professores têm como objetivo somente ensinar a matemática sem repassar para o educando um conhecimento significativo. Fazem o uso de atividades educativas que não fazem tanto sentido para o aluno. Há, ainda, profissionais que veem na matemática um ensino prático através do lúdico, em que o que se pratica dentro da sala de aula o aluno leva para a vida fora da escola.

Oliveira, Silva e CSTA (2017) ressalta que o lúdico, inserido nas aulas de matemática, resulta em um aprendizado mensurável, fugindo, assim, do ensino tradicionalista, expandindo e complementando a prática do educador em sala com os educandos. Assim, o ensino de matemática está em constante evolução. Com o decorrer dos anos, o ensino foi se adequando às mudanças, de modo que, atualmente, ensinar matemática ficou mais fácil. A ludicidade é uma forma prática e muito atraente para a criança. O brincar torna o aprendizado divertido. Sendo assim, aprender matemática ficou mais prazeroso tanto para o educando, quanto para o educador, ao lecionar. 


\subsection{Metodologias atuais de ensino da matemática nos anos iniciais do ensino fundamental}

Diante dos vários métodos de ensino disponíveis atualmente, encontrar um método que desperte o interesse dos alunos em aprender a matemática não é fácil. É necessário que o educador esteja ligado a conhecimentos científicos de modo que possa buscar novos métodos de ensino para trabalhar com os alunos em sala de aula. Que ele esteja atualizado e possa mudar sempre a metodologia e as estratégias.

O currículo escolar fornece ao professor conteúdos para que ele possa trabalhar com os alunos durante o ano letivo de que forma poderá estabelecer um método pedagógico que colabore com o processo de desenvolvimento da inteligência dos alunos que frequentam os primeiros anos do ensino fundamental.

A política pública educacional busca construir elementos centrais que conduzam o trabalho do educador. Pensando nos anos iniciais do ensino fundamental, essa política possui objetivos a serem alcançados por meio desse nível escolar, descrevendo quais condutas os educadores devem atender em suas atividades docentes. As políticas educacionais devem impulsionar a participação escolar, visando garantir o acesso à educação nos estados e nos municípios (UNYLEYA, 202I).

Vale ressaltar que na Resolução n.07/2010, dos Parâmetros Curriculares Nacionais, fixa as Diretrizes Curriculares Nacionais para o ensino fundamental de nove anos (BRASIL, 2018). Segundo os Parâmetros Curriculares Nacionais propostos em 1997, o documento formatado era dividido por dois grupos: um, de $\mathrm{I}^{\underline{\mathrm{a}}}$ a $4^{\underline{\mathrm{a}}}$ série e outro, de $5^{\underline{\mathrm{a}}}$ a $8^{\underline{\mathrm{a}}}$ série, sendo assim, um grande avanço na educação brasileira. Para o primeiro grupo, haveria uma coleção de dez volumes compostos por Português, Matemática, Ciências Naturais, História, Geografia, Educação Física e Arte, além da nomenclatura de $\mathrm{I}^{\mathrm{a}}$ série, $2^{\underline{a}}$ série e assim por diante.

A partir de 2006, com a Lei n. $11.274 / 2006$ (BRASIL, 2006), foram estabelecidas as diretrizes e bases da educação nacional e o ensino fundamental passaria a ter duração de nove anos, com matrícula obrigatória a partir dos seis anos de idade. A nomenclatura deixou de ser série e passou a ser de ano. $\mathrm{I}^{\circ}$ ano, $2^{\circ}$ ano e assim por diante.

De acordo com a orientação e com a estruturação curricular, o objetivo geral do ensino fundamental era utilizar diferentes linguagens para trabalhar com as crianças em 
sala de aula - verbal, gráfica, matemática, corporal e plástica, de modo que pudesse expressar ideias, interpretar e tirar um maior proveito das produções culturais. Tendo em vista que o aluno é a peça fundamental no ambiente educacional e seguirá o caminho orientado no currículo, deve ser preparado objetivando ao ensino (PEREIRA, 2014).

O ensino da matemática deixa de ser usual, em que a aula era típica, expositiva, o professor utilizava o quadro negro para esboçar o material, o aluno repetia as atividades no caderno, levava atividades para fazer em casa. O professor corrigia e começava tudo de tudo, como um círculo vicioso. A partir das novas diretrizes, o ensino de matemática tomou um novo rumo. O educador conduz as crianças a analisarem informações, a estabelecerem pontos iguais e diferentes, fazem uso da matemática para interpretá-las e avaliá-las. Conduz as crianças em situações práticas, organizadas, faz uso de brincadeiras, de música e até mesmo do teatro para levar conhecimento. O quadro negro dá espaço para a data show, e para a apresentação de slides; agora, o conhecimento que a criança adquire na escola leva para o dia a dia.

\subsection{A ludicidade no ensino da matemática nos anos iniciais do ensino fundamental}

Diante das dificuldades apresentadas por alguns alunos perante o aprendizado de matemática, sendo praticamente um fardo durante sua vida estudantil, surgiu a necessidade de um novo método de ensino que despertasse a curiosidade da criança e a vontade de querer aprender. Nesse contexto, surgiu a ludicidade, em que, através dos jogos, a criança é estimulada de forma sutil, agradável e também desafiadora. A matemática ensinada através da ludicidade faz com que o aprendizado se torne atrativo, leve e prazeroso. A matemática lúdica é uma ferramenta fundamental para atender à necessidade de elaborar aulas que possam ser pedagogicamente mais proveitosas e divertidas (CUNHA e SILVA, 2012).

Estudar matemática não se restringe apenas a números, mas a interpretá-los e os jogos como instrumento de auxílio no processo de ensino-aprendizagem fazem uma grande diferença. Brandão (1993) afirma que ninguém escapa da educação, seja nas ruas, nas escolas ou nas igrejas; é um conjunto de condutas que guia para interação social. 
A ludicidade, como instrumento de trabalho nas aulas de matemática, entra como facilitadora para o desenvolvimento das crianças, de modo que percam a visão negativa que possam ter da matemática. Maranhão (2004) ressalta que a ludicidade inserida nas aulas de matemática modifica o método de ensino tradicional, ampliando, assim, a prática docente dentro da sala de aula. Desenvolver a criatividade através de oficinas e de jogos tem sido a forma mais bem-sucedida de lecionar matemática, tornando as aulas mais agradáveis e de fácil compreensão.

Tanto educandos quanto educadores encontram dificuldades no ensinoaprendizagem de matemática, as quais são retratadas por vários autores. Campos (1997, p. 73) diz que o termo mais utilizado nas escolas é: "dificuldade ou problema de aprendizado”. Esse problema ou dificuldade refere-se a uma desordem no aprendizado do aluno, que pode apresentar alguma dificuldade ou limitação devido a vários fatores e não à matemática em si.

Os jogos inseridos de forma organizada, bem planejados, possibilitam um melhor raciocínio lógico que ajuda a criança na resolução de situações peculiares tanto no cotidiano escolar, quanto no próprio cotidiano, despertando, assim, um interesse maior em estudar a matemática. Usar o lúdico como ferramenta de trabalho na matemática contribui para que os alunos obtenham melhores resultados na disciplina. Cunha e Silva (2012) ressalta que, quando a ludicidade é bem trabalhada pelo educador, proporciona um trabalho mais produtivo, despertando no aluno habilidades que este até então desconhecia.

Entre as contribuições proporcionadas pelos jogos nas aulas de matemática, vale destacar: manipulação de materiais, capacidade afetiva, valores, objetos, desenvolvimento do corpo, atitudes, interesses e capacidades cognitivas. Essas capacidades contribuem para a formação de um ser humano preparado e complexo. A motivação do aluno através dos jogos é grande, pois, ao mesmo tempo em que estuda matemática, apresentará melhores atitudes e um melhor desempenho durante o processo de aprendizagem (GROENWALD, 2008).

Moyles (2002) destaca que a preparação da criança se inicia quando esta se depara com determinada situação que requer uma solução imediata, levando-a a planejar e a traçar uma solução lógica e rápida. É por meio dos jogos que as crianças expressam as emoções 
reprimidas; nos jogos é que elas têm a oportunidade de conhecer melhor os colegas de classe.

Neves (2010) pontua que a ludicidade trabalha a ansiedade da criança, fazendo com que esta possua uma melhor concentração, melhorando os relacionamentos interpessoais e a autoestima. Quando realizado de formas divertidas, o aprendizado se torna prazeroso, tendendo a diminuir diversos problemas de aprendizado apresentados pelas crianças. Enfim, a criança aprende, desenvolve, planeja, exercita, avalia, permitindo, assim, aproveitamento de todo o seu potencial.

O lúdico transporta a criança para o mundo da imaginação, desperta nela o interesse, a curiosidade, a vontade de aprender. Portanto, a ludicidade é necessária durante o ensino de matemática e não pode ser vista apenas como diversão. Em suma, os lúdicos nas aulas de matemática vieram para agregar conhecimento, experiência, para facilitar a aprendizagem e para colaborar para o desenvolvimento pessoal, cultural e social, tornandose um facilitador da comunicação, de expressão e de construção do conhecimento estudantil e uma ferramenta indispensável no processo ensino-aprendizado. Segundo Pereira (2014), o lúdico na matemática traz benefícios tanto para quem ensina, quanto para quem aprende, pois, enquanto o professor obtém uma maior produtividade em seu trabalho, ao aluno possibilita interação, atenção e melhor compreensão dos conteúdos.

\section{MATERIAL E MÉTODOS}

Através deste trabalho, pretendeu-se, pela metodologia utilizada, realizar uma revisão bibliográfica sistemática que traga, por meio de referências teóricas, o quão a ludicidade é importante no processo de ensino-aprendizagem de matemática, pois trabalhar com o lúdico torna as aulas práticas, atrativas para os alunos, e os educadores obtêm melhores resultados em sala, levando-se em conta também a situação atual que estamos vivendo.

No ano de 2020, o mundo viveu e ainda vive a disseminação do coronavírus, causando a COVID-ı9. Uma doença altamente contagiosa que tem levado milhares de pessoas a ficarem doentes e milhares a óbito. Diante desse novo cenário, a OMS decretou 
uma pandemia mundial e medidas de prevenção foram tomadas de modo que se evitasse um maior contágio por parte da população.

Nesse sentido, todos os setores têm sido afetados pela pandemia. Muitos trabalhos deixaram de ser presenciais e tornaram-se Home Office. Creches e escolas fecharam. Foi recomendado o uso de álcool gel e de máscara, o distanciamento social, evitar aglomerações, abraços e apertos de mãos. A economia mundial foi grandemente afetada. A saúde entrou em colapso. Faltaram leitos nos hospitais e nas UTI's.

Um dos setores mais afetados pela pandemia foi o educacional. As aulas deixaram de ser presenciais para serem remotas. Corpo docente, pais, responsáveis e filhos tiveram que se reinventar e se organizar diante do novo método de ensino. As salas de aulas deram lugar aos celulares, aos grupos de WhatsApp e às plataformas como o Google Meet. Muitos professores têm tido a ludicidade como grande aliada durante o processo de ensinoaprendizado. $\mathrm{O}$ material a ser estudado é passado aos alunos através de reuniões e grupos online e pais e responsáveis auxiliam os filhos para realizá-las. A ludicidade torna esse auxílio dos pais em casa mais fácil, principalmente para os que têm dificuldades em auxiliar os filhos durante as aulas de matemática.

Baseado em pesquisas bibliográficas, em artigos e em sites da internet, este estudo visa alcançar os objetivos aqui apresentados. Primeiramente, a pesquisa visa descrever teorias da importância em trabalhar a matemática através do lúdico, conforme relatado. Busca analisar situações, desde o surgimento da ludicidade aplicada em sala de aula e seus benefícios tanto para alunos, quanto para o corpo docente.

Dando continuidade, este estudo busca, através de teorias e de referências, mostrar a importância do lúdico no aprendizado infantil e de que forma a ludicidade colabora para o aprendizado e para o desenvolvimento da criança. Diante da pandemia, em aulas remotas, que benefícios o lúdico traz para quem ensina e para quem aprende?

O presente trabalho investiga a diferença entre o ensino tradicionalista de matemática e a utilização dos jogos durante as aulas. Realizou-se a partir de uma revisão bibliográfica sistemática, cujos dados são coletados e apresentados. Visa compreender que o lúdico em sala de aula vai muito além de brincar, respaldado em autores como Friedmann (1996), o qual afirma que "brincar é essencial para a criança e contribui para o 
desenvolvimento dela”. Ressalta Friedmann (I996, p. 4I): “Os jogos lúdicos permitem uma situação educativa cooperacional e interacional, ou seja, quando alguém está jogando está executando regras do jogo e ao mesmo tempo, desenvolvendo ações de cooperação e interação que estimulam a convivência em grupo".

Durante o processo de execução da pesquisa, algumas questões foram formuladas, de modo que fosse possível encontrar respostas. Questões levantadas como por que ensinar matemática através da ludicidade? Por que o lúdico é tão importante em sala de aula? Será que a criança realmente aprende brincando e jogando? As respostas a essas e a outras questões serão apresentadas e são essenciais para dar continuidade à pesquisa.

\section{RESULTADOS E DISCUSSÃO}

O desenvolvimento infantil, desde bebê, está relacionado ao ato de brincar. Ao aprender, não precisa ser diferente. Aprender e brincar ao mesmo tempo proporciona à criança maior concentração e dedicação, levando-a a aprender por prazer. As atividades lúdicas na escola, em especial nas aulas de Matemática, vêm para quebrar o tabu da matéria tida como "difícil" ou até mesmo "complicada", eliminando, assim, as aulas tradicionalistas, dando lugar a um método totalmente novo de ensino.

Através dos jogos, o professor pode utilizar peças de formas diferentes, jogos de montar casas e torres, tabuleiros, jogos de encaixar, jogos de trilhas, entre outros tantos. Essa junção de jogos possui o mesmo resultado: a brincadeira. Através deles, a criança adquire algumas habilidades, como aprender a sequência numérica, quantidades, entre outros, e, assim, obter progresso no aprendizado enquanto aprende brincando.

O jogo promove o desenvolvimento na medida em que representa o modelo pelo qual a criança integra relações Inter psíquicas, atuando num mundo repleto de objetivações humanas a serem, por ela, apropriadas. A criança coloca diante de situações lúdicas, aprende a estrutura lógica da realidade por meio da brincadeira e, deste modo, apreende também a estrutura matemática que nela faz presente (ARCE, MARTINS, 2007, p.I88).

Os brinquedos tornam possível que as crianças se informem da realidade e a construam socialmente, pois, através do faz de conta, nota que isso faz parte de sua vida. Elas criam as próprias brincadeiras a partir dos próprios pensamentos e vivências. Ressalta 
Arce e Martins (2007), por exemplo, que meninas da zona rural quando crianças brincavam com sabugos de milho, os fazendo de bonecas.

Para Costa e Soares (2015), o lúdico desempenha papel fundamental na vida da criança, tanto no desenvolvimento quando no processo de construção do conhecimento, o que facilita o aprendizado e, consequentemente, possibilita a socialização na sociedade na qual a criança está inserida.

A ludicidade é uma ferramenta muito valiosa para o professor para se alcançarem os objetivos no processo de ensino-aprendizado, principalmente nos anos iniciais da educação básica, pois propicia à criança aprender com prazer, o que é trabalhado em sala de aula, sendo suporte indispensável para o ensino. Complementa Almeida (2017) que o ensino lúdico influencia a formação infantil, propiciando o crescimento saudável, pois exige participação criativa, livre, franca e crítica, além de melhorar o aprendizado. Ao brincar, a criança se depara com inúmeros desafios e com diversas situações, de modo que possa vir a solucionar problemas, vindo, assim, a trabalhar a criatividade e a capacidade para a resolução de problemas, uma vez que tem que traçar estratégias para solucionar esses problemas.

O lúdico nas aulas de matemática, quando bem trabalhado, cria um bom clima em sala de aula, aumenta a concentração infantil, a criatividade e estimula as habilidades das crianças, proporcionando também ao professor maior produtividade durante as aulas (CUNHA e SILVA, 2012).

A matemática é uma ciência que faz parte do cotidiano, seja olhando as horas, medindo a temperatura corporal, medindo a dosagem de um medicamento, ou até mesmo fazendo compras, pois se usa todo o conhecimento em matemática. Todavia, professores notam que muitos alunos possuem algum grau de dificuldade diante da matéria. Sendo assim, buscam uma forma simples e efetiva para ensinar os alunos de modo que consigam absorver todo o conteúdo. Então, utilizam os jogos, pois, através dos jogos e das brincadeiras, como intervenção metodológica curricular, servem de suporte às aulas, pois prendem totalmente a atenção infantil de modo que as crianças querem jogar e brincar mais, ressalta Souza (200I). 
Ensinar matemática vai muito além de apenas aprender a ler e a contar os números, é desenvolver o raciocínio lógico, a criatividade, a capacidade de resolver problemas em diferentes situações, além de estimular o pensamento crítico. Assim, os jogos auxiliam no aprendizado como um incentivo ao aluno, aumentando e despertando o interesse pelo conteúdo. Isso ocorre exatamente pelo ato de brincar, pois o aluno vai assimilar o conteúdo juntamente com os demais colegas enquanto se diverte (SOUZA, 200I).

Almeida, Souza e Benedito (2020) relatam a aplicação dos jogos em exposições de conjuntos numéricos que, em um experimento com crianças do ensino fundamental II, utilizaram jogos para ensinar. Um dos jogos utilizado foi o famoso Bingo. $\mathrm{O}$ resultado do experimento realizado foi positivo e com ótimos resultados, pois ensinar através das brincadeiras aumentou o interesse e a participação dos alunos na aula e todos obtiveram um bom índice de aproveitamento na avaliação final.

Aprender de modo prazeroso propicia à criança a capacitação em construir o imaginário, e sucessivamente, distinguir o que é real, do que é imaginário. Os benefícios do lúdico não estão restritos apenas à escola, são influenciadores ao longo da vida do indivíduo. O lúdico contribui com o desenvolvimento infantil, uma vez que melhora a psicomotricidade da criança, estimula a fantasia, o imaginário, explora habilidades, melhora a socialização, entre outros. Através do lúdico, o indivíduo passa a se conhecer melhor e a conhecer, o outro (BRASIL, 2019).

Portanto, os jogos podem ser utilizados com a finalidade de facilitar o aprendizado, como construir conceitos e memorização de processos, pois, ao mesmo tempo em que joga, a criança está exercitando a capacidade de concentração, a atenção, além de aprender a elaborar hipóteses, estabelecendo alternativas diferentes, se organizando da melhor forma para solucionar os problemas.

\section{CONCLUSÃO}

Ao longo do desenvolvimento infantil, a criança, desde bebê, está em contato com a matemática, seja nas formas geométricas, nos números, entre outros elementos. Os anos iniciais do ensino fundamental são uma fase muito importante para o desenvolvimento 
infantil, pois existe uma maior probabilidade em aprender e de utilizar métodos que facilitem não só esse processo, como também o de memorização, o que é essencial.

Os jogos trazem elementos indispensáveis para o processo de ensino-aprendizado infantil, pois a criança precisa sentir prazer em aprender para poder realizar as atividades da melhor maneira possível. Nesse sentido, os jogos, além de desafiadores, estimulam a socialização infantil.

Pode-se concluir que a ludicidade na matemática desempenha papel importantíssimo para se obter sucesso na prática educativa. No entanto é necessário que corpo docente tenha clareza em relação ao conteúdo que disponibilizará para as crianças em sala de aula, de modo que a aula seja prazerosa para aprender e compreender e desperte a vontade de sempre querer saber e aprender mais.

\section{REFERÊNCIAS}

ALMEIDA, Hianne Maravilha Dantas e Sousa; SOUSA, Francisca Kelly Duarte de; BENEDITO, Rosinângela Cavalcanti da Silva. Relato de experiência: ensino médio, uso do recurso jogos no ensino dos conjuntos numéricos. VII ecmat, cajazeiras, p. I-8, 2020. Disponível em: https://drive.google.com/file/d/IMckXmUrRlFeDOThPVVERABoSI2tIdX $31 /$ view. Acesso em 16 de março de 2021.

ALMEIDA, Vagner Lopes. Matemática em sala de aula: uma proposta lúdica usando a resolução de problemas. 2017. 55f. Dissertação - Instituto de Matemática, Maceió, 2017. Disponível

em: 〈http://www.repositorio.ufal.br/bitstream/riufal/2436/r/Matem\%C3\%Argica\%20em\%20s ala\%2ode\%20aula\%20\%20uma\%2oproposta\%2ol\% $\mathrm{C}_{3} \% \mathrm{~B}$ Adica\%2ousando\%20a\%2oresolu\% $\mathrm{C}_{3} \% \mathrm{~A}_{7} \% \mathrm{C}_{3} \% \mathrm{~A}_{30} \% 20$ de\%2oproblemas.pdf $>$. Acesso em i6 de março de 202I.

ARCE, Alessandra; MARTINS, Lígia Márcia (Orgs.). Quem tem medo de ensinar na educação infantil? em defesa do ato de ensinar. Campinas, SP:

Alínea, 2007. 218 p.

BORBA, Ângela Maria. O brincar como um modo de ser e estar no mundo. In: BRASIL/MEC - Revista Criança do professor de educação infantil - Brasília: Ministério da Educação, Secretaria de Educação Básica, 2007.

BRANDÃO, Carlos Rodrigues. O que é educação? 28 ed. São Paulo, SP: Brasiliense, Coleção Primeiros Passos, 1993, p.II. 
BRASIL. Congresso Nacional. Lei de Diretrizes e Bases da Educação Nacional, atualizada até junho de 2018. Senado Federal. Disponível em: $\langle$ https://www2.senado.leg.br/bdsf/bitstream/handle/id/544283/lei_de_diretrizes_e_bases_ 2ed.pdf >. Acesso em io de março de 202I.

BRASIL, Educa Mais. Benefícios da ludicidade para as crianças. 20I9. Disponível em: https://www.educamaisbrasil.com.br/educacao/noticias/beneficios-da-ludicidade-paraas-criancas. Acesso em 02 de junho de 2021.

BRASIL. Ministério da Educação, Secretaria de Educação Básica. Orientações curriculares para o ensino médio: Ciências da natureza, matemática e suas tecnologias. Brasília, 2006.

BUENO, Silveira. Minidicionário da Língua Portuguesa. 2a edição. São Paulo. FDT, 2007, p. 500.

CAMPOS, Luciana Maria Lunardi. A rotulação de alunos como portadores de "distúrbios ou dificuldades de aprendizagem": uma questão a ser refletida. Série Ideias, São Paulo, n. 28, p.125-139, 1997 .

CORTÊS, Regis. A importância da Matemática no nosso dia a dia!. 2020. Disponível em: $\langle$ https://geniodamatematica.com.br/importancia-da-matematica-nosso-dia-dia/〉. Acesso em: 25 mar. 2021.

COSTA, Ângela Maria dos Reis Gonçalves; SOARES, Hellen Conceição Cardoso. A ludicidade no ensino da matemática nos anos iniciais do ensino fundamental I. 2015. 13 f. Texto - Colégio Atenas. Alfenas, 2015. Disponível em: <http://www.atenas.edu.br/uniatenas/assets/files/magazines/5__A_LUDICIDADE_N O_ENSINO_DA_MATEMATICA_NOS_ANOS_INICIAIS_DO_ENSINO_FUNDA MENTAL_I.pdf $>$. Acesso em o9 de março de 2021.

CUNHA, Jussileno Souza da; SILVA, José Adgerson Victor da. A importância das atividades lúdicas no ensino da matemática. 2012. Disponível em: 〈http://w3.ufsm.br/ceem/eiemat/Anais/arquivos/RE/RE_Cunha_Jussileno.pdf〉. Acesso em i6 de março de 202I.

FRIEDMANN, Adriana. Brincar: crescer e aprender: o resgate do jogo infantil. São Paulo. Moderna, 1996.

GROENWALD, Cláudia Lisete Oliveira; TIMM, Úrsula Tatiana. Utilizando curiosidades e jogos matemáticos em sala de aula. 2008. Disponível em: 〈https://www.somatematica.com.br/artigos/aI/ >. Acesso em I2 de março de 202I.

MARANHÃO, Diva Nereira Marque Machado. A importância do brincar e seu significado. In: MARANHÃO, D.N.M.M. Ensinar brincando: aprendizagem pode ser uma grande brincadeira. Rio de Janeiro: WAK, 2004. 
MOYLES, Janet R. Só brincar? O papel do brincar na Educação Infantil. Porto Alegre: Artmed, 2002.

NETO, José Emídio da Silva; PACHECO, Willyan Ramon de Souza. A ludicidade como ferramenta potencializadora do processo de ensino-aprendizagem da matemática. Artigo. Campina Grande, v.2, n.2, p. I-I2, Jan/Set. 2017. Disponível em: <https://www.editorarealize.com.br/editora/anais/conedu/2017/TRABALHO_EVo73_M Di_SAI3_ID6228_09092017112844.pdf $>$. Acesso em 09 de março de 202I.

NEVES, Diogo Sá das. O Brincar E Sua Função Na Intervenção Psicopedagógica Em Instituições Escolares: O Que Dizem Os Psicopedagogos? Faculdade SENAC - 2010.

OLIVEIRA, Williamar Figueiredo de; SILVA, Mary Rodrigues da; CSTA, Jessica Flaíne dos Santos. $O$ ensino da matemática através da ludicidade: jogos e oficinas: The teaching of mathematics through the deceit: games and offices. Artigo. Araripina, p.I - I2, 2017. Disponível em: 〈https://sescpe.org.br/revistaconhecereproduzir/arquivos/xv/WILLIAMAR\%2oFIGUE REDO.pdf $>$. Acesso em I2 de março de 202I.

PEREIRA, Priscila. O currículo e as práticas pedagógicas. 2014. 36f. Monografia SOCIEDADE CULTURAL E EDUCACIONAL DE ITAPEVA FACULDADE DE CIÊNCIAS SOCIAIS E AGRÁRIAS DE ITAPEVA. Disponível em: 〈http://fait.revista.inf.br/imagens_arquivos/arquivos_destaque/myLjgW5XRwu6olI_2015 -2-5-I4-23-30.pdf $>$. Acesso em Io de março de 202I.

SANTOS, Joelson Honorato. O lúdico na aprendizagem escolar. 2020. Disponível em: 〈http://dspace.bc.uepb.edu.br/jspui/bitstream/123456789/2040/I/PDF\%2O\%20Joelson\%20Honorato\%2odos\%20Santos\%20Silva.pdf >. Acesso em: I6 março de 2021.

SANTOS, Lázaro Santana. A importância dos jogos e brincadeiras de Matemática na Educação Infantil. Texto, 2014. Disponível em: 〈https://www.pedagogia.com.br/textos/index.php?id=40〉. Acesso em I6 de março de 2021.

SILVA, Luciano Martins da. Ludicidade e matemática: um novo olhar para aprendizagem. In: Psicologia \& Saberes. v. 4, n. 5, 2015. p. 10-22. Disponível em: 〈https://revistas.cesmac.edu.br/index.php/psicologia/article/view/726\#: :text=O\%20al icerce\%2odo\%2osaber\%20de,papel\%20do\%2odocente\%2onesse\%2oprocesso>. Acesso em: Io março de 2021.

SOUZA, Maria José Araújo. Informática Educativa na Educação Matemática: Estudo de geometria no ambiente do Software Cabri-Géomètre. 20oI. $154 \mathrm{f}$. Dissertação (Pós Graduação em Educação Brasileira) - Faculdade de Educação da Universidade Federal do Ceará - UFC. Fortaleza, 20or. 
UNYLEYA, Faculdade. $O$ que são as políticas educacionais?. 2021. Disponível em: 〈https://blog.unyleya.edu.br/insights-confiaveis/o-que-sao-as-politicas-educacionais/〉. Acesso em: 29 mar. 2021. 